Araştırma Makalesi-Research Article

\title{
Farklı Anaçlar Üzerine Aşılı Şaraplık Üzüm Çeşitlerinde Fidan Randıman ve Kalite Özelliklerinin Belirlenmesi
}

\author{
Seda Sucu ${ }^{1 *}$, Adem Yağc1 ${ }^{2}$ \\ Geliş / Received: 02/06/2020 \\ Revize / Revised: 26/08/2020 \\ Kabul / Accepted: 23/09/2020 \\ $\overline{\mathbf{o z}}$ \\ Bağlarda filoksera zararlısının varlığından dolayı asma fidanı üretimi pratik ve ekonomik olarak aşı ile \\ yapılmaktadır. Asma fidanı üretiminde farklı anaç-çeşit kombinasyonları fidan randıman ve kalitesini önemli \\ derecede etkilemektedir. 2018 yılında yapılan bu çalışmada; Cabernet Sauvignon, Cabernet Franc, Merlot, Pinot \\ Noir, Syrah ve Narince şaraplık üzüm çeşitleri; Kober 5BB, 110R, 1103P anaçları üzerine aşılanmış, tüplü asma \\ fidanı olarak yetiştirilmiş ve kombinasyonlara göre fidan randıman ve kalitesi belirlenmiştir. Kombinasyonlara \\ göre en yüksek fidan randımanı kendi kökü üzerine Narince (\% 92.7) çeşidinden elde edilmiştir. Kalite \\ parametrelerinden sürgün uzunluğu bakımından kendi kökü üzerinde Cabernet Sauvignon $(46.2 \mathrm{~cm})$, yaş-kuru \\ sürgün ağırlığı bakımından Cabernet Sauvignon/1103P (17.1 g; $3.46 \mathrm{~g}$ ), kök uzunluğu bakımından Merlot /110 R \\ (18 cm), yaş-kuru kök ağırlığı bakımından Syrah/110 R (3.3 g; $0.21 \mathrm{~g})$ kombinasyonları ön plana çıkmıştır.
}

Anahtar Kelimeler- Aşılama, Kök, Sürgün, Randıman, Parafin

\footnotetext{
1*Sorumlu yazar iletişim: seda.sucu@gop.edu.tr (https://orcid.org/0000-0002-5187-5048)

Bahçe Bitkileri, Ziraat Fakültesi, Tokat Gaziosmanpașa Üniversitesi

2İletişim: adembaba06@gmail.com (https://orcid.org/0000-0002-3650-4679)

Bahçe Bitkileri, Ziraat Fakültesi, Tokat Gaziosmanpaşa Üniversitesi
} 


\title{
Determination of Sapling Yield and Quality Characteristics of Grape Varieties Grafted on Different Rootstocks
}

\begin{abstract}
Due to the presence of phylloxera in vineyards, the production of vine saplings is practically and economically made by grafted. Different rootstock-variety combinations in grapevine production significantly affect the yield and quality of sapling. In this study conducted in 2018, Cabernet Sauvignon, Cabernet Franc, Merlot, Pinot Noir, Syrah, and Narince wine grape varieties were grafted on Kober 5BB, 110R, 1103P rootstocks grown as scuba vines and sapling yield and quality were determined according to combinations. According to the combinations, the highest sapling yield was obtained from Narince (92.7\%) variety on its root. Cabernet Sauvignon own root $(46.2 \mathrm{~cm})$ in terms of shoot length, among the quality parameters, wet-dry shoot weight Cabernet Sauvignon/1103 $\mathrm{P}(17.1 \mathrm{~g} ; 3.46 \mathrm{~g})$, root length in terms of Merlot/110 R (18 cm), wet-dry root weight Syrah /110 R (3.3 g; $0.21 \mathrm{~g})$ combinations came to the fore.
\end{abstract}

Keywords- Graftted, Root, Shoot, Final Take, Paraffin 


\section{GİRIŞ}

Asma (Vitis vinifera L.) dünyanın en eski kültür bitkilerinden birisidir. Avrupa kıtasına özgü olan bu tür, insanlık tarihi ile birlikte kıtalar arasında yayılmış ve yeni coğrafyalarda asma ailesine (Vitis ssp.) ait farklı türlerin belirlenmesi ile bağcllı kültürü zenginleşmiştir [1]. Asmanın meyvesi olan üzüm Dünyadaki en önemli meyvelerden birisidir. Bu durum üzümün dünyadaki meyveler arasında, alan ve üretim açısından ilk sırada yer alması ile kendini göstermektedir [2,3]. Üzümün önemli bir başka özelliği de değerlendirilme şekillerine göre farklı (sofralık, şaraplık-şıralık, kurutmalık) yetiştirilme koşullarına, damak tatlarına, uygulamalara, kültürlere hitap eden çeşitlere sahip olmasıdır [4].

Tarımsal açıdan bu derece önemli olan bir bitkinin çoğaltılması da oldukça önemlidir. Aşılama odunsu bitkilerde rutin olarak kullanılan bir çoğaltma tekniğidir [5,6]. Asma ekonomik ve pratik olarak aşı ile çoğaltılmaktadır. Önceleri kendi kökleri üzerine kolayca çoğaltılabilen asma bitkisi için filoksera zararlısının varlığı ilebirlikte aşı ile çoğaltma zorunlu hale gelmiş̧ir. Filoksera bağclık açısından oldukça önemli bir zararlıdır ve Vitis vinifera L. ise filoksera zararlısına karşı oldukça duyarlıdır [7].

Bağcılıkta aşılama yetiştirilmek istenen çeşidin, Amerikan asma anaçları üzerine masa başında veya yerinde aşılanması ile gerçekleştirilmektedir [8]. Anaçlar; fidanın kök sistemini oluşturmaktadır. Her bir anacın su ve mineral emilimi farklıdır. Bu durum fizyolojik süreci ve dolayısıyla da asma verim ve kuvvetini de etkilemektedir [5,9].

Anaç kullanımının birtakım avantajları olduğu gibi dezavantajları da mevcuttur. Asma anaçlarının her birinin fizyolojik, biyokimyasal özellikleri farklı olduğu için direk ya da dolaylı olarak anaç-çeşit kombinasyonunu da etkiler.[9]. Așılamada anaç-çeşit uyumu; asmanın büyümesini, verimini, kanopisini, kuvvetini, meyve kalitesini ve bunun gibi birçok özelliğini etkilemektedir $[10,11,12,13,14]$. Bu nedenle anaçların ve çeşitlerin fizyolojik özelliklerinin bilinerek uygun anaç-çeşit kombinasyonunun seçilmesi oldukça önemlidir [15]. Ayrıca, anaçlar çeşidin ekonomik, karakteristik ve biyokimyasal özelliklerini de etkilemekte anaç-çeşit kombinasyon ilişkisi, toprak ve iklim özellikleri ile de son derece alakalı olmaktadır [16]. Aşılı asma fidanı üretimi birçok basamaktan oluşmaktadır ve bu aşamaların her biri fidan randıman ve kalite parametrelerini önemli derece de etkilemektedir. Bununla birlikte kullanılan bitkisel materyallerin özellikleri de randımanı etkilemektedir.

Farklı anaç- çeşit kombinasyonlarının denendiği birçok çalışma [16,17,18,19,20,21] mevcuttur. Yapılan bu çalışma ile farklı anaçlar üzerine aşılı şaraplık üzüm çeşitlerinde fidan randıman ve kalite özelliklerinin belirlenmesi amaçlanmıştır.

\section{II.MATERYAL VE YÖNTEM}

\section{A. Materyal}

Çalışma 2018 y1lında Tokat Gaziosmanpaşa Üniversitesi (TOGÜ) Ziraat Fakültesi’ne ait aşıllama ünitesi ve seralarında yürütülmüştür.

Kalemler ve anaçlar Manisa Bağcılık Araştırma Enstitüsü’nden temin edilmiştir (Şubat-2018). Çalışmada şaraplık üzüm üretiminde oldukça önemli yere sahipolan Cabernet Sauvignon, Cabernet Franc, Merlot, Pinot noir, Syrah ve Narince şaraplık üzüm çeşitleri, 5BB, 110R ve 1103P anaçları üzerine aşılanmıştır.

\section{B. Yöntem}

Aşılama zamanına kadar geçen sürede çelikler ve kalemler $\% 80-95$ nem ve $0-4{ }^{\circ} \mathrm{C}$ ' de soğuk hava deposunda muhafaza edilmiştir [23, 24, 25, 26]. Soğuk hava deposundan çıkarılan anaçlık çeliklerde göz köreltme işlemlerinin (15 Mart), ardından aşı zamanından hemen önce ise kaybedilen suyun kazandırılması adına anaçlık çelikler 2 gün, kalemlik çelikler ise 1 gün süre ile suda bekletilmişlerdir [8]. Daha sonra sırası ile kaybedilen suyun geri kazandırıldığ bitkisel materyale; $50{ }^{\circ} \mathrm{C}$ de 30 dakika sıcak su uygulaması (termoterapi), ardından masabaşı omega aşı yöntemi ile aşılama, parafinleme, katlama işlemleri uygulanmıştır (18-20 Mart).Belirtilen uygulamalara tabi tutulan fidanlar, ardından kaynaştırma odasına alınmıştır (nem oranı \%85-95; sıcaklık: ilk 3 gün $28-29^{\circ} \mathrm{C}$, 15 gün $25-26^{\circ} \mathrm{C}$ ve 3 gün $22-24^{\circ} \mathrm{C}$; havalandırma: 12 saatte bir saat). Kaynaştırma sonrası 2. parafinleme yapılan 


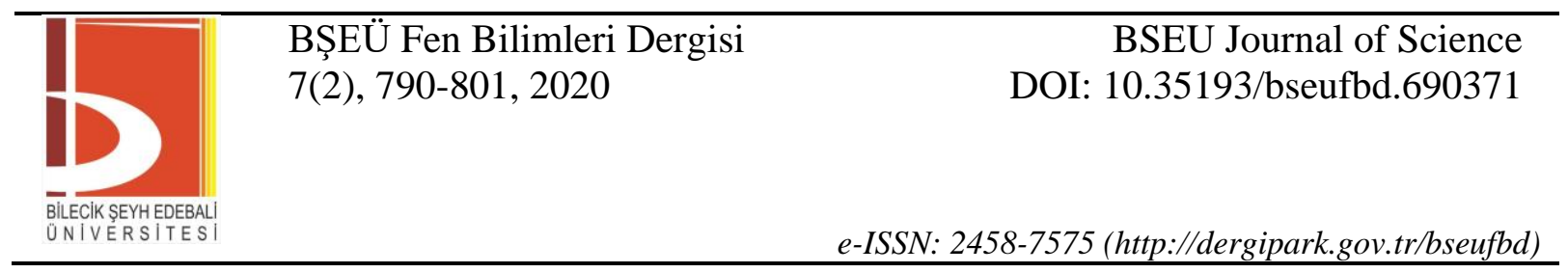

fidanlar içlerinde torf:perlit (1:1 v/v) karışımı bulunan tüplere dikilerek (22 Nisan), dört- beş hafta boyunca sera ortamında büyümeleri sağlanmıştır [26, 27, 28, 29, 30] (Şekil 1, 2, 3 ve 4) .

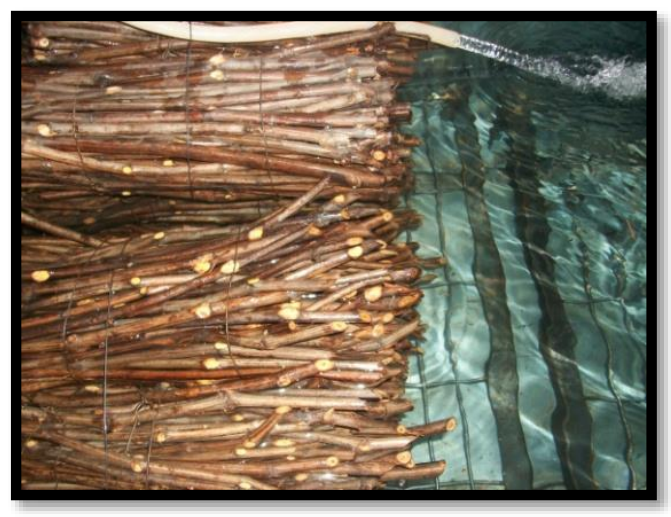

Şekil 1. Anaçlık ve kalemlik çeliklerin suda bekletilmesi

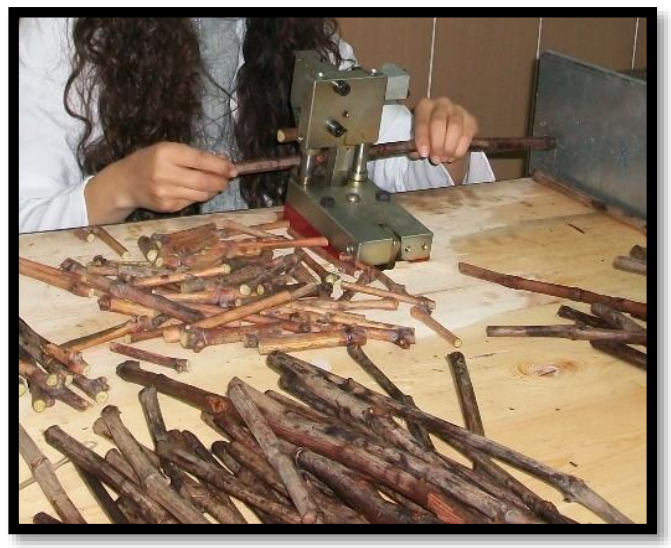

Şekil 2. Masabaşı omega aşı makinesi ile aşılama

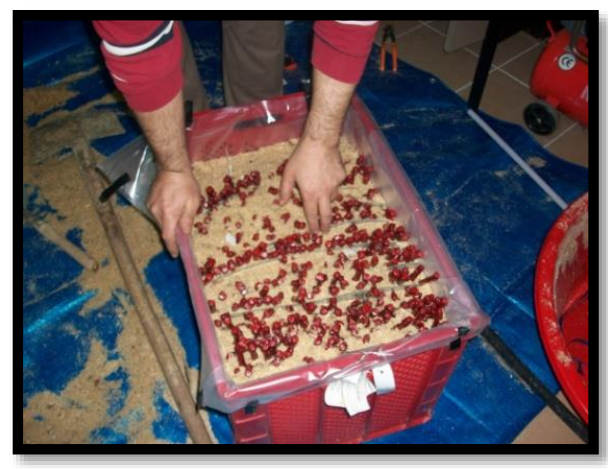

Şekil 3. Aşılanmış olan anaç ve kalemlik çeliklerin talaş içinde katlama sandıklarına yerleştirilmesi 


\begin{tabular}{|c|c|c|}
\hline & $\begin{array}{l}\text { BŞEÜ Fen Bilimleri Dergisi } \\
7(2), 790-801,2020\end{array}$ & $\begin{array}{l}\text { BSEU Journal of Science } \\
\text { DOI: } 10.35193 / \text { bseufbd.690371 }\end{array}$ \\
\hline & & 88-7575 (http://dergipark.gov.tr/bseufbd) \\
\hline
\end{tabular}

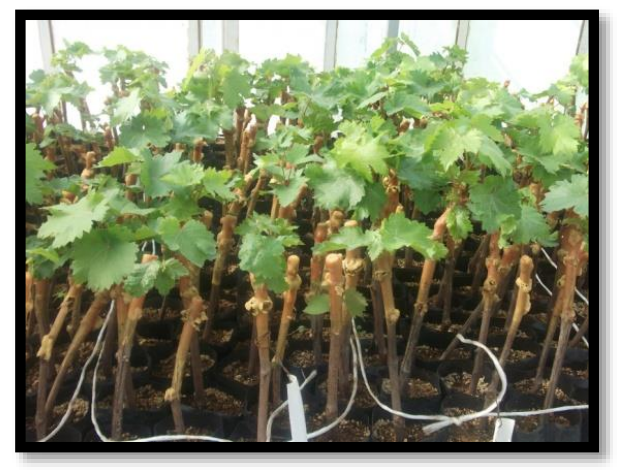

Şekil 4. Serada ortamında büyümekte olan tüplü asma fidanları

Dikilen fidanlar yaklaşık beş hafta boyunca gelişmeye bırakılmış olup sonrasında elde edilen fidanlarda aşağıdaki özelliklere bakılmıştır.

- Fidan randımanı (\%): Fidan randımanına ait formül aşağıdaki gibidir (F.R; Fidan randımanı, D.F.S; dikilen fidan sayısı; Ç.F.S; Çıkan fidan sayısı);

$$
\mathrm{FR}=(\mathrm{DFS} / \mathrm{ÇFS}) \times 100
$$

- Kök uzunluğu (cm): Fidanlarda oluşan kökler, anaç gövdesinden kök uç kısmına kadar olan kök uzunlukları cetvel ile ölçülmüştür.

- Sürgün uzunluğu $(\mathrm{cm})$ : Fidanlarda oluşan sürgünlerin dip kısmından uç kısmına kadar olan sürgün uzunlukları cetvel ile ölçülmüştür.

- Sürgün-kök yaş ağırlığı (g): Fidan kökleri ve sürgünleri budama makası ile kesilmiş, yıkanmış ve gölge bir yerde bitki yüzey suyu kurutulmuş ve $0.01 \mathrm{~g}$ hassasiyetli terazide tartılarak belirlenmiştir.

Sürgün-kök kuru ağırlığı (g): yaş ağırlıkları alınan kök ve sürgünler oda sıcaklığında 48 saat, daha sonra $65{ }^{\circ} \mathrm{C}$ sıcaklıkta etüv içinde sabit ağırlığa gelinceye kadar ( 48 saat) bekletilmiş $0.01 \mathrm{~g}$ hassasiyetli terazide tartılmıştır.

1) Istatistik Analiz: Deneme bölünmüş parseller deneme desenine göre yapılmış olup elde edilen veriler varyans analizine tabii tutulmuş ve ortalamaların karşılaştırılmasında LSD testinden faydalanılmıştır. Çalışmada 4 anaç (kendi kökü dahil) x 6 çeşit x 3 tekerrür x 30 çelik olmak üzere toplam 2.160 adet bitkisel materyal kullanılmıştır. Fidan randımanının belirlenmesi için bütün bitkisel materyaller dikkate alınırken sürgün ve kök ile ilgili parametrelerin belirlenmesinde, her tekerrür için 10 adet fidan olmak üzere toplamda 720 fidan kullanılmıştır.

\section{BULGULAR VE TARTIŞMA}

Gerçekleştirilen çalışmanın çeşit, anaç ve çeşit-anaç interaksiyonuna ait fidan randıman ve kalite değerleri Şekil 5, Şekil 6, Şekil 7, Çizelge 1, Çizelge 2 ve Çizelge 3 'de verilmiştir.

Toplam fidan randıman değerleri anaçlara, çeşitlere ve anaçxçeşit interaksiyonuna göre önemli derecede etkilenmiştir. Çeşitler bazında fidan randımanı \%77.8 (Syrah) ile \%84.90 (Pinot noir) arasında olurken anaçlar bazında ise\%69.90 (110 R) ile \%91.40 (kendi kökü) arasında değişim göstermiştir. Anaç ve çeşit interaksiyonuna bakıldığında ise kendi köklerinde yetişen Narince çeşidinde en iyi randıman yakalanırken (\%92.70) 5BB üzerine aşılı Syrah çeşidinde en düşün randıman değeri elde edilmiştir (\%68.10) (Şekil 5, Şekil 6, Şekil 7). 


\begin{tabular}{|c|c|c|}
\hline & $\begin{array}{l}\text { BŞEÜ Fen Bilimleri Dergisi } \\
7(2), 790-801,2020\end{array}$ & $\begin{array}{l}\text { BSEU Journal of Science } \\
\text { DOI: } 10.35193 / \text { bseufbd.690371 }\end{array}$ \\
\hline $\begin{array}{l}\text { BüLECIKEYYHEDEALI } \\
\text { UNIVERSITESI }\end{array}$ & & 58-7575 (http://dergipark.gov.tr/bseufbd) \\
\hline
\end{tabular}

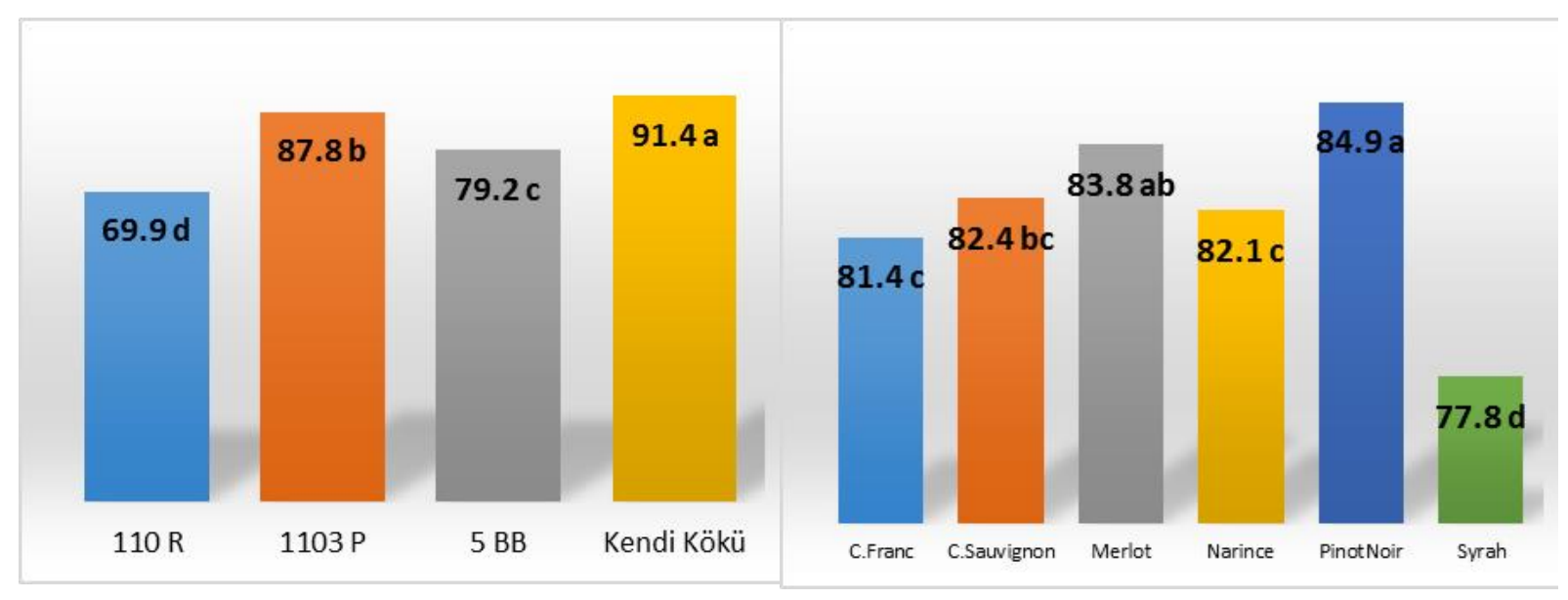

Şekil 5. Anaçlara ait toplam fidan randımanı

$\operatorname{LSD}_{(0.05)}: 2.0$
Şekil 6. Çeşitlere ait toplam fidan randıman

$\operatorname{LSD}_{(0.05)}: 1.5$

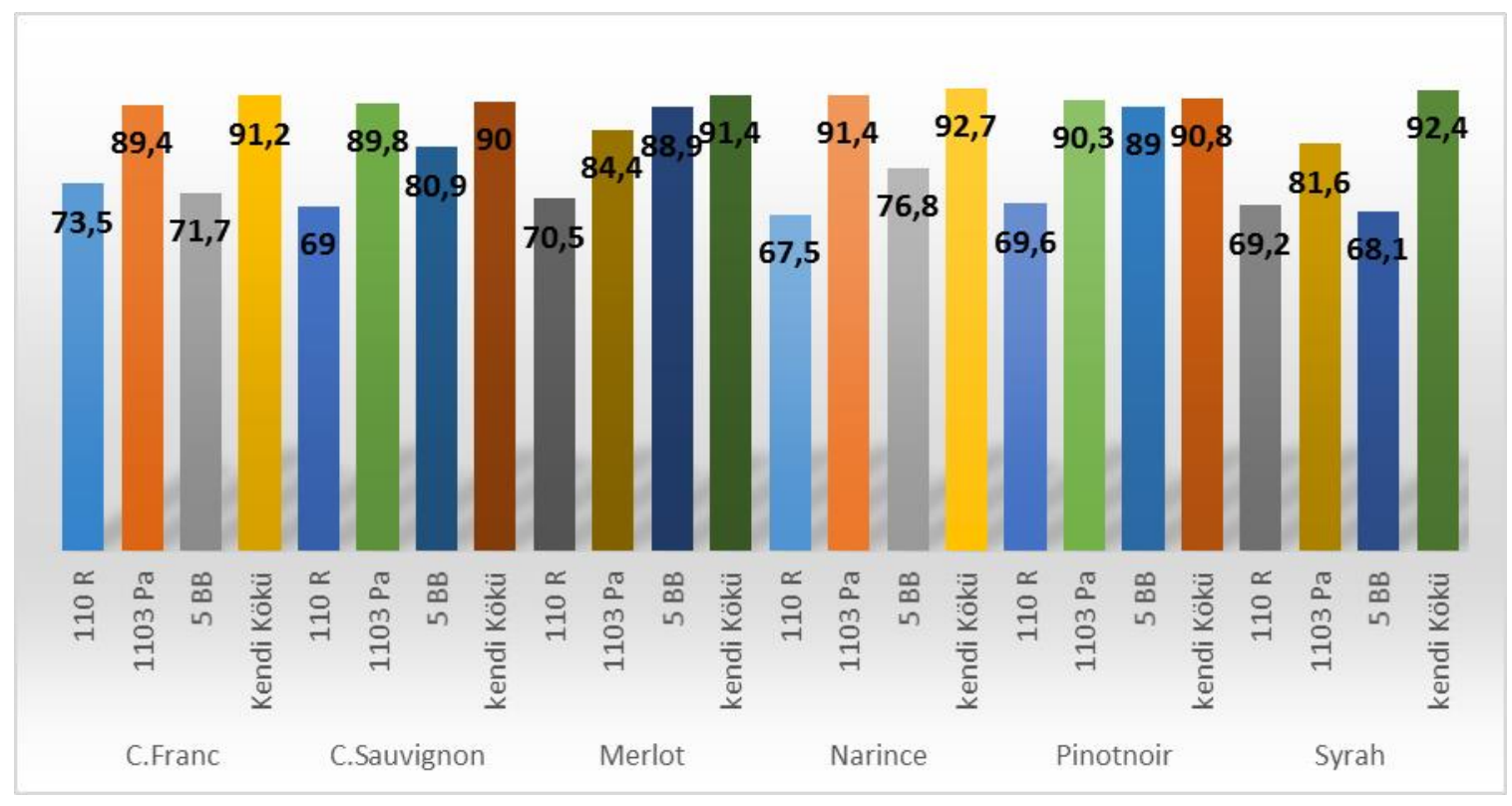

Şekil 7. Anaç x çeşit kombinasyonlarına ait toplam fidan randımanı

Kalite parametreleri incelendiğinde çeşitler bakımından; en uzun sürgün değeri $44.10 \mathrm{~cm}$ ile Cabernet Sauvignon çeşidinde ölçülürken diğer çeşitler arasında fark meydana gelmemiştir. Çeşitlerin yaş ve kuru sürgün ağırlı̆̆ı sırasıyla $2.39 \mathrm{~g}-11.90 \mathrm{~g}$ (Cabernet Sauvignon) ile $1.39 \mathrm{~g}-6.9 \mathrm{~g}$ (Narince) arasında; kök uzunluğu ile 9.60 $\mathrm{cm}$ (Cabernet Sauvignon) ile $14.50 \mathrm{~cm}$ (Syrah); yaş kök ağırlığ 1 ise $1.50 \mathrm{~g}$ (Cabernet Franc) ile $2.80 \mathrm{~g}$ (Syrah) arasında değer almıştır (Tablo 1). Anaçlar baz alındığında yaş ve kuru sürgün ağırlığında 1103 P (2.22 g;11.30 g) anacı ön plana çıkarken, yaş kök ağırlığı bakımından $110 \mathrm{R}(2.30 \mathrm{~g})$ anacı ön plana çıkıı̧tır. Sürgün uzunluğu, kök uzunluğu, kuru kök ağırlı̆̆ı bakımından rakamsal olarak farklılıklar olsa da bu farklar istatistik açıdan önem arz etmemiştir (Tablo 2). Fidan kalite parametrelerinden; kök uzunluğu açısından Merlot/1103 Pa kombinasyonu en yüksek $(18 \mathrm{~cm})$ değeri gösterirken Pinot-Noir/5BB kombinasyonu en düşük değeri $(6.70 \mathrm{~cm})$ göstermiş̧tir. 
Sürgün uzunluğu, yaş sürgün ağırlığı, kuru sürgün ağırlığı, yaş kök ağırlığı ve kuru kök ağırlığı bakımından farklar istatistiki açıdan önemli bulunmamıştır (Tablo 3).

Tablo 1. Çalışmaya konu olan çeşitlerin fidan kalite değerleri

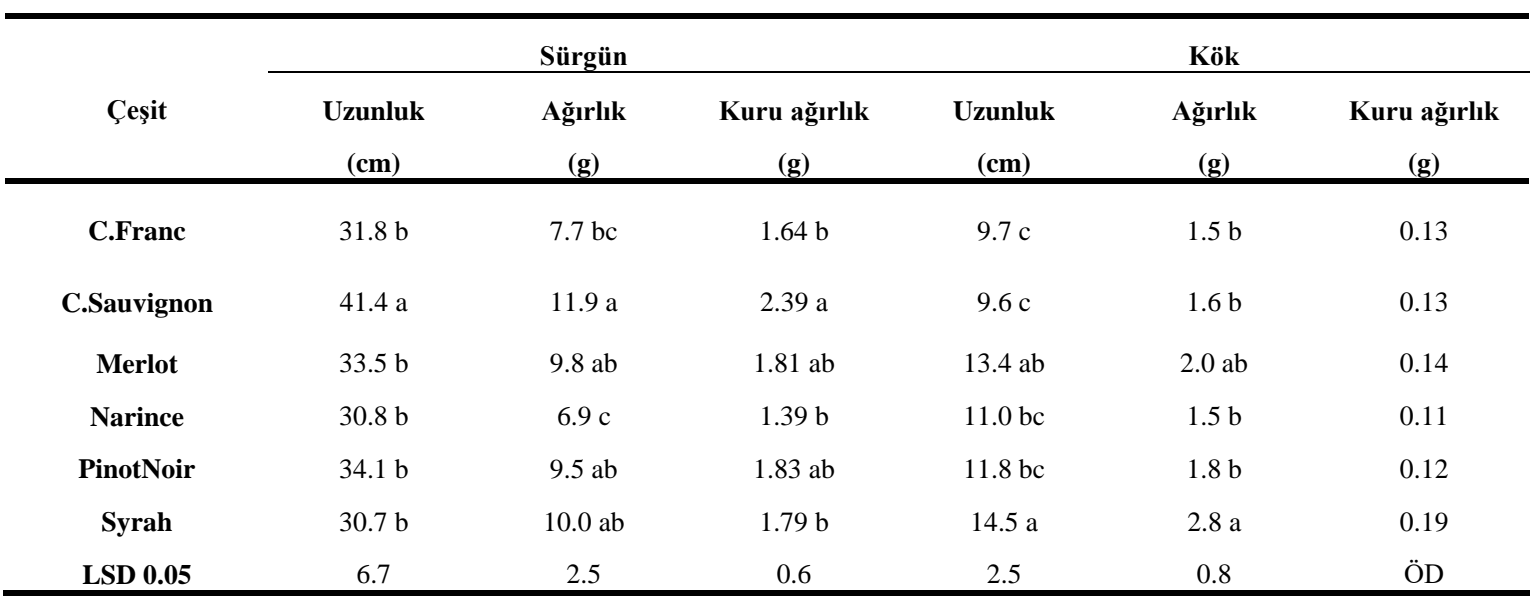

Aynı sütunda farklı küçük harfi alan çeşitler arası fark istatistiksel olarak önemlidir $(\mathrm{p}<0.05)$

Tablo 2. Çalışmaya konu olan anaçların fidan randıman ve kalite değerleri

\begin{tabular}{|c|c|c|c|c|c|c|}
\hline \multirow[b]{2}{*}{ Anaç } & \multicolumn{3}{|c|}{ Sürgün } & \multicolumn{3}{|c|}{ Kök } \\
\hline & $\begin{array}{c}\text { Uzunluk } \\
\text { (cm) }\end{array}$ & $\begin{array}{c}\text { A ğırlık } \\
\text { (g) }\end{array}$ & $\begin{array}{c}\text { Kuru ağırlık } \\
\text { (g) }\end{array}$ & $\begin{array}{c}\text { Uzunluk } \\
\text { (cm) }\end{array}$ & $\begin{array}{c}\text { Ağgrirlık } \\
\text { (g) }\end{array}$ & $\begin{array}{c}\text { Kuru ağırlık } \\
\text { (g) }\end{array}$ \\
\hline $110 R$ & 31.9 & $10.1 \mathrm{ab}$ & $1.97 \mathrm{a}$ & 12.3 & $2.3 \mathrm{a}$ & 0.16 \\
\hline $1103 \mathrm{P}$ & 36.1 & $11.3 \mathrm{a}$ & $2.22 \mathrm{a}$ & 11.6 & $2.1 \mathrm{a}$ & 0.15 \\
\hline 5 BB & 31.8 & $8.7 \mathrm{bc}$ & $1.79 \mathrm{a}$ & 10.3 & $1.6 \mathrm{ab}$ & 0.12 \\
\hline Kendi Kökü & 35.2 & $7.1 \mathrm{c}$ & $1.25 \mathrm{~b}$ & 12.4 & $1.5 \mathrm{~b}$ & 0.11 \\
\hline LSD (0.05) & ÖD & 2.2 & 0.5 & ÖD & 0.40 & ÖD \\
\hline
\end{tabular}

Aynı sütunda farklı küçük harfi alan çeşitler arası fark istatistik olarak önemlidir $(\mathrm{p}<0.05)$ 


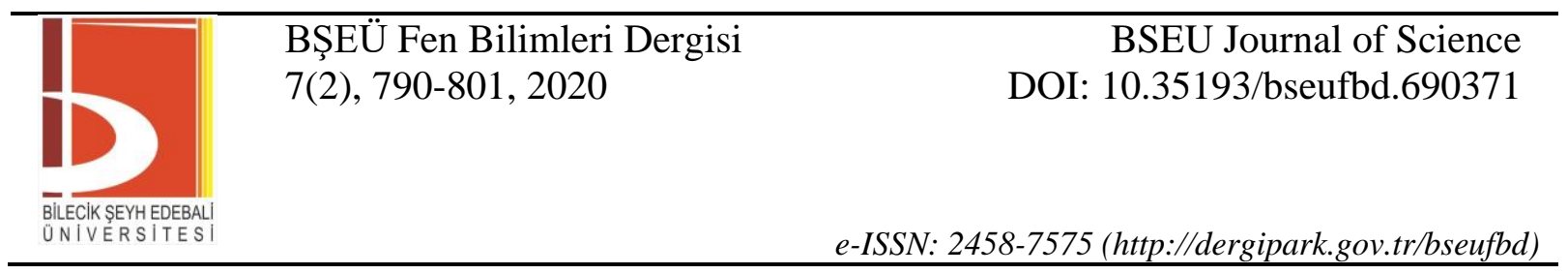

Tablo 3. Çalışmaya konu olan çeşit anaç kombinasyonlarının kalite özellikleri

\begin{tabular}{|c|c|c|c|c|c|c|c|}
\hline \multirow[b]{2}{*}{ Çeşit } & \multirow[b]{2}{*}{ Anaç } & \multicolumn{3}{|c|}{ Sürgün } & \multicolumn{3}{|c|}{ Kök } \\
\hline & & $\begin{array}{c}\text { Uzunluk } \\
\text { (cm) }\end{array}$ & $\begin{array}{l}\text { Ağırlık } \\
\text { (g) }\end{array}$ & $\begin{array}{c}\text { Kuru ağırlık } \\
\text { (g) }\end{array}$ & $\begin{array}{c}\text { Uzunluk } \\
\text { (cm) }\end{array}$ & $\begin{array}{l}\text { Ağırlık } \\
\text { (g) }\end{array}$ & $\begin{array}{c}\text { Kuru ağırlık } \\
\text { (g) }\end{array}$ \\
\hline \multirow{4}{*}{ C.Franc } & $110 \mathrm{R}$ & 24.3 & 5.9 & 1.40 & $10.0 \mathrm{c}-\mathrm{e}$ & 1.7 & 0.18 \\
\hline & $1103 \mathrm{~Pa}$ & 30.9 & 7.8 & 1.73 & $10.0 \mathrm{c}-\mathrm{e}$ & 1.4 & 0.11 \\
\hline & $5 \mathrm{BB}$ & 33.4 & 9.2 & 2.06 & $10.0 \mathrm{c}-\mathrm{e}$ & 1.9 & 0.13 \\
\hline & Kendi Kökü & 38.7 & 7.9 & 1.36 & $8.0-\mathrm{de}$ & 1.1 & 0.09 \\
\hline \multirow{4}{*}{ C.Sauvignon } & $110 \mathrm{R}$ & 42.1 & 11.6 & 2.34 & $7.3 \mathrm{e}$ & 1.2 & 0.09 \\
\hline & $1103 \mathrm{~Pa}$ & 41.0 & 17.1 & 3.46 & 13.3 a-e & 3.1 & 0.24 \\
\hline & $5 \mathrm{BB}$ & 36.5 & 8.2 & 1.94 & $10.0 \mathrm{c}-\mathrm{e}$ & 13 & 0.14 \\
\hline & Kendi Kökü & 46.2 & 10.7 & 1.81 & $7.7 \mathrm{e}$ & 0.9 & 0.06 \\
\hline \multirow{4}{*}{ Merlot } & $110 \mathrm{R}$ & 35.2 & 12.0 & 2.36 & $18.0 \mathrm{a}$ & 3.0 & 0.23 \\
\hline & $1103 \mathrm{~Pa}$ & 36.0 & 9.2 & 1.60 & $8.3 \mathrm{de}$ & 1.4 & 0.08 \\
\hline & $5 \mathrm{BB}$ & 32.4 & 11.2 & 2.07 & $16.7 \mathrm{a}-\mathrm{c}$ & 2.1 & 0.12 \\
\hline & Kendi Kökü & 30.2 & 6.9 & 1.22 & $10.7 \mathrm{~b}-\mathrm{e}$ & 1.6 & 0.11 \\
\hline \multirow{5}{*}{ Narince } & $110 \mathrm{R}$ & 27.9 & 7.3 & 1.32 & $8.7 \mathrm{de}$ & 1.3 & 0.07 \\
\hline & $1103 \mathrm{~Pa}$ & 37.8 & 11.1 & 2.28 & $11.7 \mathrm{a}-\mathrm{e}$ & 2.3 & 0.16 \\
\hline & $5 \mathrm{BB}$ & 238 & 50 & 111 & $80 \mathrm{de}$ & 12 & 012 \\
\hline & DD & 25.0 & 3.0 & 1.11 & $0.0 \mathrm{co}$ & 1.2 & 0.12 \\
\hline & Kendi Kökü & 33.8 & 4.0 & 0.85 & $15.7 \mathrm{a}-\mathrm{c}$ & 1.2 & 0.09 \\
\hline \multirow{5}{*}{ Pinotnoir } & $110 \mathrm{R}$ & 31.4 & 10.8 & 2.19 & 13.0 a-e & 3.3 & 0.20 \\
\hline & $1103 \mathrm{~Pa}$ & 39.5 & 11.1 & 2.21 & $10.0 \mathrm{c}-\mathrm{e}$ & 1.5 & 0.08 \\
\hline & & & & & & & \\
\hline & $5 \mathrm{BB}$ & 35.5 & 9.9 & 1.88 & $6.7 \mathrm{e}$ & 1.3 & 0.09 \\
\hline & Kendi Kökü & 29.9 & 6.1 & 1.02 & $17.3 \mathrm{ab}$ & 1.2 & 0.11 \\
\hline \multirow{5}{*}{ Syrah } & $110 \mathrm{R}$ & 30.4 & 13.0 & 2.20 & $16.7 \mathrm{a}-\mathrm{c}$ & 3.3 & 0.21 \\
\hline & $1103 \mathrm{~Pa}$ & 31.4 & 11.7 & 2.05 & $16.0 \mathrm{a}-\mathrm{c}$ & 3.0 & 0.20 \\
\hline & & & & & & & \\
\hline & $5 \mathrm{BB}$ & 28.9 & 8.5 & 1.67 & $10.7 \mathrm{~b}-\mathrm{e}$ & 2.1 & 0.15 \\
\hline & Kendi Kökü & 32.2 & 6.9 & 1.24 & $14.7 \mathrm{a}-\mathrm{d}$ & 2.8 & 0.20 \\
\hline $\operatorname{LSD}_{(0.05)}$ & & ÖD & ÖD & ÖD & 6.9 & ÖD & ÖD \\
\hline
\end{tabular}


Fidan üretiminde üretimde randıman değerleri anaç ve çeşitlere göre değişebileceği birçok araştırıcı tarafından belirtilmiştir [31; 32; 33; 34]. Örneğin; Dardeniz ve Şahin çalışmalarında 5BB, 140Ru, 41B ve 1103P anaçları üzerine Uslu ve Yalova İncisi üzüm çeşitleri ile yaptığı çalışmada; en yüksek fidan randımanını 41B ve 5BB üzerine aşılı Uslu çeşidinde sırasıyla \%44.61 ve \%37.47 olarak belirlemişler ve farklılığın çeşit ve anaç kombinasyonlarına göre değişebileceğini vurgulamışlardır [17]. Ağaoğlu ve Çelik çalışmalarında Hafızali, Hamburg Misketi ve Hasandede üzüm çeşitlerini 5BB ve 99R anaçları üzerine aşılamışlardır. Toplam fidan randımanının \%20-60 arasında değiştiğini belirlemişlerdir [26]. Yıldırım ve arkadaşları 41 B üzerine aşıladıkları çeşitlerde fidan randımanını Cabernet Sauvignon'da \%60.30, Merlot'da \%59.30, Boğazkere'de \%57.80 ve Chardonnay'de \%56.50 olarak elde etmişlerdir [35]. Baydar ve Ece (2005) yapmış oldukları çalışmalarında en yüksek fidan randımanı değerini Razak1/Kober 5 BB (\%61.00), Razak1/SO4 (\%59.00), Italia/SO4 (\%58.00) ve Alphonse Lavallée/SO4 (\%52.33) aşı kombinasyonlarından elde ederken, diğer kombinasyonlardan \%11.33-34.00 arasında değişen oranlarda fidan randımanı elde edilmiştir [36]. Araştırıcılara göre fidan randımanlarının arasındaki farklılıklara; kullanılan çeşit ve anaçların farklılığı yanında, bitkisel materyalin alındığı/geldiği yer, bunların saklanma koşulları, aşılama ve katlama tekniği, parafinleme, harç materyalleri, bakım işlemleri vb. birçok faktör etki etmiş olabilir. Balcı ve Yağcı yaptıkları çalışmada fidan randımanında aşılama işlemi randımanı \% 7.50 oranında azalttığını bildirmektedir [37]. Bu çalışmada da kendi kökleri üzerinde elde edilen fidan randımanları bütün kombinasyonlarda daha yüksek bulunarak benzer sonuçlar elde edilmiştir.

Fidan çalışmalarında kullanılan çeşit, anaç ve çeşit/anaç kombinasyonlarına göre; kuru kök ağırlıkları, stoma sayısı, kök gelişim düzeyi, odunlaşma düzeyi, aşı noktası kalınlıkları gibi parametrelerde [20, 24, 26, 38, 39,40 , ] farklılıklar olabilmektedir.

5BB, 140Ru, 41B ve 1103P anaçları üzerine Uslu ve Yalova İncisi üzüm çeşitlerinin aşılandığ bir çalışmada sürgün uzunluğu bakımından çeşit anaç kombinasyonlarındaki fark istatistiksel açıdan önemli bulunmuştur, bizim çalışmamızda da sürgün uzunluğu bakımından çeşitler açısından fark istatistiksel olarak önemli bulunurken anaçlar ve çeşit-anaç kombinasyonlarında önemli bulunmamıştır. Soltekin ve arkadaşlarının yaptıkları bir çalışma da 41 B anacı üzerine Sultan 1, Aktın Sultani ve Saruhan bey çeşitlerini aşılamış ve sıcaklık uygulamasının fidan randıman ve kalitesi üzerine etkilerine bakmışlardır. Yaptıkları çalışmada kullanılan kalite parametrelerinden sürgün uzunluğu, yaş-kuru kök ağırlığı bakımından farklar istatistiki açıdan önemli bulunmuştur [41]. Bizim çalışmamızda sürgün uzunluğu açısından yukarıda bahsedilmiştir. Diğer parametreler bakımından ise yaş kök ağırlığı bakımından çeşit ve anaç fidan kuru kök ağırlıklarındaki farklılık istatistiksel açıdan önemli, kök ağırlığı bakımından önemsiz bulunmuştur.

Yapılan bu çalışma ile yukarıda verilen çalışmalar uyum içerisinde olup; kullanılan anaç-çeşit kombinasyonlarına göre fidan randıman ve kalitesi değişebilmektedir.

\section{IV.SONUÇ}

Bu çalışma ile aşağıdaki sonuçlar çıkarılabilir.

- Fidan üretiminde çeşit-anaç kombinasyonuna göre fidan randımanı değişsebilir.

- Aşılı fidanlarda bitkinin toprak üstü aksamını oluşturan çeşitler, sürgün gelişiminde esas rolü oynamaktadır. Fakat sürgün içerisindeki kuru maddeyi oluşturan bileşiklerin birikiminde sürgün yanında kök sistemini oluşturan anaçlarında önemli bir katkısı vardır.

- Fidanların kök uzunluğu ve yaş kök ağırlığı, üzerine aşılı çeşitler tarafından önemli derecede etkilenmektedir.

- Çeşitlerin kök uzunluğuna olan etkisi anaçlara ve çeşitlere göre farklılık gösterirken kök yaş ağırlığ1 anaçlara göre istatistik olarak değişim göstermemektedir.

- Kuru kök ağırlığı değeri, çeşitlere, anaçlara ve bunların interaksiyonuna göre farklı olmaması fidanların kısıtlı bir alanda gelişmeye bırakılması nedeni ile olabilir. Nitekim bağ yerinde anaçların kök sistemlerinin farklı olması bilinen bir durumdur. 


\section{KAYNAKLAR}

[1] Kunter, B., \& Keskin, N. (2018). Üzümün Antioksidan ve Ayurvedik Önemi, Uluslararası Avrasya Doğal Beslenme ve Sağlıklı Yaşam Zirvesi, Ankara, Türkiye, 12-15 Temmuz, pp.382-387.

[2] Anlı, R. E. 2006. Bağlar Güzeli. İstanbul, Üzüm ve Üzüm Kültürü Yapı Kredi Yayınları, 238 sayfa.

[3] Treutter, D. (2010). Managing phenol contents in crop plants by phytochemicalfarming and breeding-visions and constraints. Int. J. Mol. Sci. 11, 807-857.

[4] Çelik, S. (2011). Bağcılık (Ampeloloji). Avcı Ofset, İstanbul, $428 \mathrm{~s}$

[5] Soar, C.J., Dry, P.R., \&Loveys, B.R. (2006). Scion photosynthesis and leaf gas exchange in L. cv. Shiraz: mediation of rootstock effects via xylem sap ABA. Aust. J Grape Wine Res. 12, 82-96.

[6] Koundouras, S., Hatzidimitriou, E., Karamolegkou, M., Dimopoulou, E., Kallithraka,S., Tsialtas, J.T., Zioziou, E., Nikolaou, N., \&Kotseridis, Y. (2009). Irrigation and rootstock effects on the phenolic concentration and aroma potential of Vitis vinifera L. cv Cabernet Sauvignon grapes. J. Agric. Food Chem. 57, 7805-7813.

[7] Jackson, D.I. \& Lombard, P.B. (1993). Environmental and management practices affecting grape composition and wine quality: a review. American Journal of Enology and Viticulture , 44, 409-430.

[8] Çelik, H., Ağaoğlu, Y.S., Fidan, Y., Marasalı, B. \& Söylemezoğlu, G. (1998). Genel Bağc1lık, Ankara, SunfidanA.Ş. Mesleki Kitaplar Serisi:1, 253 s.

[9] Satisha, J., Ramteke, S.D., \&Karibasappa, G.S. (2007). Physiological and biochemical characterisation of grape rootstocks. S. Afr. J. Enol. Vitic. 28, 163-168.

[10] Ezzahouani, A., \&Williams, L.E. (1995).The influence of rootstock on leaf waterpotential, yield, and berry composition of Ruby seedless grapevines. Am. J.Enol. Vitic. 46, 559-563.

[11] Koundouras, S., Tsialtas, I.T., Zioziou, E., \&Nikolaou, N. (2008). Rootstock effects on the adaptive strategies of grapevine (Vitis vinifera L. cv. Cabernet-Sauvignon) undercontrasting water status: leaf physiological and structural responses. Agric.Ecosyst. Environ, 128, 86-96.

[12] Jones, H. G. (2012). How do rootstocks control shoot water relations? New Phytologist, 194 (2), $301-303$.

[13] Tecchı, M.A., Paılı-Pıres, E.J., Terra, M.M., Teıxeıra, L.A.J., \&Leonel, S. (2013). Característicasfísicas eacúmulo de nutrientespeloscachos de 'NiagaraRosada' em vinhedosnaregião de Jundiaí. RevistaBrasileira de Fruticultura, 29, 621-625.

[14] Souza, C.R., Mota, R.V., França, D.V.C., Pimentel, R.M.A., \& Regina, M.A. (2015). Performance of Cabernet Sauvignon grafted onto different rootstocks during the autumn-winter season in Brazilian southeast. Scientia Agricola, 72, 138-146.

[15] Martinez-Ballesta., M. C., Alcaraz-Lopez C., Muries B., Mota-Cadenas C., \& Carvajal M. (2010). Physiologicalaspects of rootstockscioninteractions. Sci. Hortic. 127, 112-118.

[16] Vršič, S., Pulko, B., \&Kocsis, L. (2016). Effects of rootstockgenotypes on compatibility, biomass, andtheyield of Welschriesling Vol. 43, 2016 (2), 92-99. 
[17] Dardeniz, A. \& Şahin, A.O. (2005). Aşılı asma fidanı üretiminde farklı çeşit ve anaç kombinasyonlarının vejetatif gelişme ve fidan randımanı üzerine etkileri. Tarım ve Köyişleri Bakanlığı, Atatürk Bahçe Kültürleri Merkez Araştırma Enstitüsü Müdürlüğ̈̈ Dergisi, Bahçe. 43 (2), 1-9.

[18] Bahar, E., Korkutal, İ., \&Kök, D. (2008). Hidroponik Kültür ve Fidanlık Koşullarında Yetiştirilen Aşılı Asma Fidanlarının Karbonhidrat Ve Azot İçerikleri İle Bağdaki Tutma Performansları Üzerine Araştırmalar Akdeniz Üniversitesi Ziraat Fakültesi Dergisi, 21(1), 15-26.

[19] Çakır, A., Karaca, N., Sıdfar, M., Baral, Ç. \& Söylemezoğlu, G. (2013). Sultani Çekirdeksiz Üzüm Çeşidinin Farklı Amerikan Asma Anaçları ile Aşı Tutma Oranının Belirlenmesi YYÜ Tar Bil Derg (YYU)J AgrSci) 23(3), 229-235.

[20] Şen, A. \&Yağcı, A. (2016). Tüplü Asma Fidanı Üretiminde Farklı Köklendirme Yerlerinin Fidan Randıman ve Kalitesi Üzerine Etkileri. Meyve Bilimi 3(1), 22-28.

[21] Sucu, S. \& Yağcı, A. (2017). Bazı Asma Anaçları ve Bu Anaçlar Üzerine Aşı1ı Sultani Çekirdeksiz Çeşidinde Fidan Randımanı ve Kalite Özelliklerinin Belirlenmesi Ege Üniv. Ziraat Fak. Derg.,54 (1), 53-59.

[22] Çelik, H. (2006). Üzüm Çeşit Kataloğu. Ankara. Sun Fidan AŞ Mesleki Kitaplar Serisi:3, 165 s.

[23] Becker, H. (1971). Neure Ergebnisse aus Untersuchungen Über die Techonologie der Lagerung van Rebenvermehrunsut. Probleme der Rebenveredlung, Heft. 8, 29-48.

[24] Gerhard, R., Cheng-Yung, C. \& Schneider, F. (1971). Probleme Der Reben-Veredlung. Heft 8, 9-27.

[25] Sievers, E. (1971). Neue Wege bei der Versongang der Rebenveredlung mit Edelreis material. Weinberg und Keller, 18,253-279.

[26] Ağaoğlu, Y.S \&Çelik, H. (1978). Bazı Amerikan Asma Anaçlarında Ethrel Uygulamaları ve Dikim Şekillerinin Köklenme Üzerine Etkileri. Ankara Üniversitesi Ziraat Fakültesi Yıllı̆̆l, Cilt:27

[27] Hamilton, R. (1997). Hot Water Treatment of Grapevine Propagating Material. The Australian Grapegrower Winemaker, 400,21-22.

[28] Çelik, H. (1983). Sera Koşullarında Tüplü Asma Fidanı Üretimi, Türkiye II. Bağcılık ve Şarapçılık Sempozyumu, Manisa s, 3-8. Türkiye 1.Fidancılık Sempozyumu Bildirileri s. 52.

[29] Akman, İ. \& Ilgın, C. (1987). Tüplü Fidan Üretiminde Başarıyı Etkileyen Faktörler, TÜBİTAK Türkiye 1.Fidancilık Sempozyumu Bildirileri, s. 52.

[30] Aslan, K.A., Özcan, S., Kösetürkmen, S., Yağcı, A., Sakar, E., Bekişli, M.İ. \&Kılıç, D. (2015). Gaziantep İli Asma Fidanı Üretiminde Farklı Çeşit/Anaç Kombinasyonlarının Karşılaştırılması. Selçuk Tarım ve Gıda Bilimleri DergisiA. 27 (1), 210-216.

[31] Cangi, R., Doğan, A., Balta, M. \& Yarılgaç, T. (1999). Aş1lı̈ Asma Fidanı Üretiminde Farklı Parafin Uygulamalarının Aşı Kaynaşmasının Seyri ve Fidan Randımanı Üzerine Etkileri. Türkiye III. Ulusal Bahçe Bitkileri KongreKitabı, 983-988.

[32] Cangi, R., Balta, F., \&Doğan, A. (2000). Asılı Asma Fidanı Üretiminde Kullanılan Katlama Ortamlarının Fidan Randıman ve Kalitesi Üzerine Etkilerinin Anatomik ve Histolojik Olarak İncelenmesi Turk J Agric For 24, 393-398. 
[33] Yağc1, A., Alpaslan, K., \&Özcan, S. (2016). Gaziosmanpaşa Üniversitesi Ziraat Fakültesi Dergisi33 (2), 125-134.

[34] Günen, E. \&Altındişli, A. (2017). Cabernet Sauvignon Üzüm Çeşidinin Bazı Amerikan Asma Anaçları ile Aşı Kombinasyonlarının Örtü Altı ve Açıkta Yetiştiricilik Koşullarında Tüplü Fidan Performanslarının Değerlendirilmesi. Ege Üniv. Ziraat Fak. Derg, 54 (1), 91-99.

[35] Yıldırım, M., Dardeniz, A., Gökbayrak, Z., Türkmen, C., Yıldırım, F., \&Tunçel, R. (2011). Farklı üzüm çeşitlerindeki üniform kültürel uygulamaların aşılı asma fidanı randıman ve gelişimi üzerine etkileri. Çanakkale Tarımı Sempozyumu Kitapçığı (Dünü, Bugünü ve Geleceği), 434-442.

[36] Baydar, N.G., \&Ece, M. (2005). Isparta Koşullarında Aşılı Asma Fidanı Üretiminde Farklı Çeşit/Anaç Kombinasyonlarının Karşılaştırılması. Süleyman Demirel Üniversitesi Fen Bilimleri Enstitüsü Dergisi, 9 (3).

[37] Balcı, M., \&Yağcı, A. (2018). Asma Fidanı Üretiminde Ön Bekletme ve Alttan Isıtma Uygulamalarının Randıman ve Kalite Üzerine Etkileri Bahçe 47 (Özel Sayı 1: Türkiye 9. Bağcıllk Ve Teknolojileri Sempozyumu), 393-400.

[38] Fidan, Y., \&A. Eriş. (1972). Bazı Önemli Sofralık ve Şaraplık Üzüm Çeşitlerinde Bir Senelik Dalların Özellikleri Üzerinde Araştırmalar. Ankara Üniversitesi Ziraat Fak. Ylllığl Yıl:22, Fasikül:3-4, 1972.

[39] Kısmalı, İ., \& Karakır, N. (1990). Asma Fidanı Elde Edilmesinde Kalite ve Randıman Arttırma Olanakları Üzerinde Araştırmalar. Doğa, Tarım ve Ormancllık Dergisi, 14, 107-115.

[40] Çelik, S., Delice, A. \& L. Arın. (1991). Fidanlık Koşullarında Aşılı Köklü Asma Fidanı Üretimi. Doğa-Tr. J. of Agricultural and Foresty 16, 507-518.

[41] Soltekin, O., Savaş, Y., Özcan.T. E., \&Kacar, E. (2017). Termoterapi Uygulamasının Tüplü Aş11ı Asma Fidanı Üretiminde Fidan Randıman ve Kalitesi Üzerine Etkileri. Türk Tarım ve Doğa Bilimleri Dergisi, 4 , (1), 30-39. 